\title{
Minimal access rapid deployment aortic valve replacement: Initial single-center experience and 12-month outcomes
}

Markus Schlömicher, MD, Peter Lukas Haldenwang, MD, Vadim Moustafine, MD, Matthias Bechtel, MD, PhD, and Justus Thomas Strauch, MD, PhD

Objectives: A single-center observational study was initialized to evaluate the feasibility of rapid deployment aortic valve replacement using the Edwards Intuity valve system (Edwards Lifesciences Corp, Irvine, Calif) in a minimally invasive setting. A total of 60 implantations have been performed at the Ruhr University Hospital Bergmannsheil using a minimal access technique. We present the first short-term and 12-month clinical and hemodynamic results.

Methods: Aortic valve replacement using a partial sternotomy was performed in all patients. Patients' mean age was $75.5( \pm 6.2)$ years. The mean logistic European System for Cardiac Operative Risk Evaluation was $8.4 \pm 4.2$, and $39 \%(\mathrm{n}=23)$ of patients were female. A clinical follow-up for echocardiographic assessment was performed after 12 months.

Results: The 30-day mortality rate was $1.7 \%(\mathrm{n}=1)$. The mean postoperative transprosthetic gradient was $11.7( \pm 4.3) \mathrm{mm} \mathrm{Hg}$. The mean effective orifice area was $1.8( \pm 0.3) \mathrm{cm}^{2}$. One case of higher-grade regurgitation (aortic insufficiency $>+1$ ) occurred. The late mortality rate was $5.1 \%(3 / 59)$. After 12 months, the mean transprosthetic gradient was $10.3( \pm 3.8) \mathrm{mm} \mathrm{Hg}$. The mean effective orifice area of $1.8( \pm 0.3) \mathrm{cm}^{2}$ remained unchanged. The mean implantation time was $9( \pm 3)$ minutes. The mean crossclamp time was $26( \pm 7)$ minutes. The average bypass time was $56( \pm 16)$ minutes.

Conclusions: Reproducible short crossclamp and bypass times were achieved in a minimally invasive setting. The valve shows good hemodynamic performance comparable to other sutureless or rapid deployment valves. Nevertheless, future follow-up investigation has to be awaited to gain more data concerning durability and safety issues. (J Thorac Cardiovasc Surg 2015;149:434-40)

See related commentary on pages $441-2$.

The treatment of aortic valve disease has undergone tremendous developments in the past decade, driven by innovative minimally invasive transcatheter implantation techniques, which also influence the number of patients being referred for conventional aortic valve replacement (AVR) surgery in Europe. ${ }^{1}$ Transcatheter aortic valve implantation was developed as a solution for a high-risk patient group not suitable for conventional AVR, and has become a less-invasive alternative to AVR even for a medium- to low-risk patient population. Several publications

From the Department of Cardiothoracic Surgery, Ruhr University Hospital Bergmannsheil, Bochum, Germany.

Disclosures: Justus Thomas Strauch reports consulting fees from Edwards and lecture fees from Edwards and Medtronic. All other authors have nothing to disclose with regard to commercial support.

Received for publication May 4, 2014; revisions received Sept 7, 2014; accepted for publication Sept 27, 2014; available ahead of print Nov 7, 2014

Address for reprints: Markus Schlömicher, MD, Department of Cardiothoracic Surgery, Ruhr-University Hospital Bergmannsheil, Bürkle de la Camp Platz 1, 44789 Bochum, Germany (E-mail: markus.schloemicher@bergmannsheil.de).

0022-5223/\$36.00

Copyright (c) 2015 by The American Association for Thoracic Surgery

http://dx.doi.org/10.1016/j.jtcvs.2014.09.118 report surprisingly good short-term results comparable to conventional AVR within a high-risk group., ${ }^{2,3}$

The rate of minimal access AVR is disappointingly low, with less than $10 \%$ of all AVR procedures being performed via a limited access technique. ${ }^{1}$ The major point of criticism is the increased complexity of the operation leading to a significant increase of myocardial ischemic and cardiopulmonary bypass times, which might outweigh the positive effects of the minimal access technique, such as scar reduction, shorter ventilation times, shorter intensive care unit and hospital lengths of stay, less blood loss, and faster return to routine life activities. ${ }^{4-6}$

Three different rapid deployment or sutureless valves recently have been introduced for conventional AVR aiming at a reduction of crossclamp times and the simplification of conventional AVR procedures: the Enable valve system (Medtronic, Inc, Minneapolis, Minn), the Perceval $\mathrm{S}$ valve system (Sorin Biomedica Cardio Srl, Sallugia, Italy), and the Edwards Intuity valve system (Edwards Lifesciences Corp, Irvine, Calif). ${ }^{7-13}$ Myocardial ischemic times less than 1 hour are shown to be reproducibly achievable and to have excellent hemodynamic performance, low paravalvular leakage, and low pacemaker rates. Nevertheless, long-term results concerning durability have to be awaited. ${ }^{7-13}$ 


\section{Abbreviations and Acronyms \\ $\mathrm{AI}=$ aortic insufficiency \\ $\mathrm{AVR}=$ aortic valve replacement \\ $\mathrm{EOA}=$ effective orifice area}

A comprehensive minimally invasive program with a particular focus on minimal access aortic surgery was established in 2010 in the Department of Cardiothoracic Surgery, Ruhr University Hospital Bergmannsheil. Since then, $99 \%$ of the conventional AVR procedures have been performed using a minimal access technique. The preferred access is a $\mathrm{j}$-shaped partial sternotomy into the third to fourth right intercostal space with a minimized skin incision.

At the Ruhr University Hospital Bergmannsheil, the Edwards Intuity valve has been implanted in 60 patients by using a minimal access technique. The European Conformity mark in Europe was received in February 2012. It combines the proven long-term safety and efficacy of the Carpentier-Edwards Perimount (Edwards Lifesciences Corp) platform with anchoring techniques derived from transcatheter valves. It is a stented trileaflet bioprosthesis composed of bovine pericardium that has been preserved in a buffered glutaraldehyde solution and mounted on a balloon-expandable stent frame that is covered by a polyester sealing cloth, anchoring the valve in the subannular region after balloon expansion. The available sizes are 19,21, 23, 25, and $27 \mathrm{~mm}$. The Edwards Intuity valve system consists of the bioprosthesis, a delivery system, and a balloon catheter, which is used to expand the stent frame of the valve after placement within the aortic annulus and the outflow tract. We present operative data and clinical outcomes after 30 days and 12 months.

\section{PATIENTS AND METHODS}

A nonrandomized single-center observational study was initialized to evaluate the feasibility of rapid deployment valve AVR in a minimally invasive setting. The ethical committee approved the study, and all patients gave written informed consent.

Between March 2012 and August 2013, 60 patients underwent minimally invasive AVR using the Edwards Intuity Valve System. Indications for rapid deployment AVR were as follows: stenotic aortic valve disease defined by a valve area less than $0.8 \mathrm{~cm}^{2}$ and mean transaortic gradients of more than $40 \mathrm{~mm} \mathrm{Hg}$. Contraindications for the use of the Edwards Intuity Valve System were aneurysmal dilatation $(45 \mathrm{~mm})$ or dissection of the ascending aorta, active endocarditis, bicuspid aortic valve, and recent myocardial infarction ( $<90$ days).

The mean age was $75.5( \pm 6.2)$ years. The mean logistic European System for Cardiac Operative Risk Evaluation was $8.4 \%( \pm 4.2)$, and $39 \%$ were female (Table 1). A clinical follow-up for echocardiographic assessment of the valve performance was conducted after 12 months.

A standard j-shaped partial sternotomy into the third to fourth right intercostal space was performed with a mean skin incision length of $7.1 \pm 1.4 \mathrm{~cm}$. The aorta was directly cannulated via the incision, and the venous cannula was tunneled subxiphoidally and inserted into the right atrial appendage. The vent was placed in the right upper pulmonary vein, and cardioplegia was administered in an antegrade fashion using a standard cannula and cold blood cardioplegia. A standard hockey stick aortotomy usually was chosen to expose the native aortic valve. After decalcification and the sizing procedure, 3 guiding sutures were placed at the nadir of each aortic sinus.

The extent of decalcification is comparable to standard AVR. Excessive decalcification should be avoided. One has to keep in mind that a resulting annular defect cannot be sealed with valve sutures. A rather stepwise decalcification technique is recommendable. If there are 2 valve size choices, further decalcification offers the opportunity to implant the larger valve size. The ideal annulus should be approximately cylindrical and free of defects. Obvious defects or noncylindrical distortions as a result of the decalcification procedure may lead to a paravalvular leak or annular rupture. Exact sizing is most important for all rapid deployment and sutureless valves because of the inability of conforming the annulus to the shape of the sewing ring, as in conventional AVR surgery. Oversizing may lead to valve luxation during balloon inflation. Undersizing causes paravalvular leakage.

Braided, nonpledged sutures that were stitched through the annulus in a standard everting technique and through 3 marked positions on the sewing cuff were used. The valve with the attached delivery system was lowered into place in the annulus under direct vision with the guiding sutures snared with a tourniquet. Finally, the balloon catheter was inserted through the holding device and locked into place. The balloon was inflated using saline for 10 seconds. The pressure in the balloon should be 3 to $5 \mathrm{~atm}$. The sutures were tied after removing the entire holding device. Closure of the aortotomy was carried out in a typical double-layer fashion. Postoperative oral anticoagulant therapy was administered for a 3-month postoperative period in accordance with recent Guidelines for Management of Patients with Valvular Heart Disease. ${ }^{14}$

\section{Follow-up}

Clinical and echocardiographic follow-up examinations were performed at the time of discharge and after 12 months. The following procedures were performed at the 12-month follow-up: physical examination and assessment of complications and transthoracic echocardiography. Transvalvular gradients were determined using the Bernoulli equation. Prosthetic aortic regurgitation was classified as none or trace, mild, moderate, or severe according to recent guidelines. ${ }^{15}$ Postoperative outcomes were assessed in accordance with the Valve Academic Research Consortium definitions. ${ }^{16}$

\section{Statistics}

Continuous variables are presented as mean and standard deviation. Categoric variables are summarized as the number and percentage of subjects in each category. Complications are described for the early (30 days postoperatively) and late ( $>30$ days postoperatively) periods. Early and late complications are calculated as the number of events divided by the number of subjects receiving implants. The Student $t$ test was used for paired data testing. Transvalvular pressure gradients were performed as a point-to-point statistical analysis.

\section{RESULTS}

A mean crossclamp time of $26 \pm 7$ minutes was achieved with a mean implantation time of $9 \pm 3$ minutes (Table 2). The implantation time was defined as the interval between the first annular stitch and the last knot of the guiding sutures being tied after the valve had been brought into position and expanded. The mean cardiopulmonary bypass time was $56 \pm 16$ minutes. The shortest AVR procedure was 
TABLE 1. Baseline characteristics of patients $(n=60)$

\begin{tabular}{lc}
\hline \multicolumn{1}{c}{ Parameter } & Mean \pm SD or $\%(\mathbf{n})$ \\
\hline Age, mean \pm SD (y) & $75.5 \pm 6.2$ \\
Logistic euroSCORE, mean \pm SD (\%) & $8.4 \pm 4.2$ \\
euroSCORE II, mean \pm SD $(\%)$ & $3.5 \pm 1.3$ \\
LVEF, mean \pm SD (\%) & $58 \pm 14.4$ \\
Female gender $(\%)$ & $38(\mathrm{n}=23)$ \\
NYHA class $\geq 3(\%)$ & $75(\mathrm{n}=45)$ \\
PVD (\%) & $23(\mathrm{n}=14)$ \\
COPD (\%) & $8(\mathrm{n}=5)$ \\
Renal insufficiency (creatinine clearance & $15(\mathrm{n}=9)$ \\
$\quad<85$ mL/min) $(\%)$ & $5(\mathrm{n}=3)$ \\
Stroke (with residual paralysis) $(\%)$ & $92(\mathrm{n}=55)$ \\
Hypertension & $83.6 \pm 18.7$ \\
Body weight, mean \pm SD (kg) & $166.5 \pm 20.8$ \\
Body height, mean \pm SD (cm) & \\
\hline COPD, Chronic obstructive pulmonary disease; euroSCORE, European System \\
for Cardiac Operative Risk Evaluation; LVEF, left ventricular ejection fraction; \\
NYHA, New York Heart Association; $P V D$, peripheral vascular disease; SD, standard \\
deviation.
\end{tabular}

performed with a crossclamp time of 16 minutes, whereas the longest procedure required a crossclamp time of 47 minutes.

An overall procedural success rate of $98.1 \%$ (59/60) was achieved. In 1 patient, intraoperative echocardiography after weaning from cardiopulmonary bypass showed severe paravalvular leakage with resulting grade 3 aortic insufficiency (AI). After reclamping and explantation of the Intuity valve, a conventional stented pericardial valve (Edwards Perimount) was implanted instead. The rest of the postoperative course was uncomplicated. All procedures were performed as a single AVR procedure using a minimal access technique via partial sternotomy.

TABLE 2. Intraoperative data

\begin{tabular}{lc}
\hline \multicolumn{1}{c}{ Parameter } & Mean \pm SD or $\%(\mathbf{n})$ \\
\hline Valve size $(\mathrm{mm})(\mathrm{n}=60)$ & $6(\mathrm{n}=4)$ \\
$19(\%)$ & $29(\mathrm{n}=17)$ \\
$21(\%)$ & $29(\mathrm{n}=17)$ \\
$23(\%)$ & $27(\mathrm{n}=16)$ \\
$25(\%)$ & $10(\mathrm{n}=6)$ \\
$27(\%)$ & \\
Procedures $(\mathrm{n}=60)$ & $100(\mathrm{n}=60)$ \\
AVR only $(\%)$ & $100(\mathrm{n}=60)$ \\
Partial sternotomy $(\%)$ & $9 \pm 3$ \\
Valve implant time (min) & $26 \pm 7$ \\
Crossclamp time (min) & 16 \\
Shortest crossclamp time (min) & 47 \\
Longest crossclamp time (min) & $56 \pm 12$ \\
CPB time (min) & $98(\mathrm{n}=59)$ \\
Procedural success rate $(\%)$ & $2(\mathrm{n}=1)$ \\
Conversion to conventional valve & \\
implantation $(\%)$ & \\
AVR, Aortic valve replacement; $C P B$, cardiopulmonary & bypass; $S D$, standard \\
deviation. &
\end{tabular}

All-cause and valve-related early mortality were $1.7 \%$ $(1 / 60)$ and $1.7 \%$ (1/60), respectively. In this particular case, 1 patient died of pericardial tamponade postoperatively, which led to cardiopulmonary resuscitation and immediate reoperation (valve related). Bleeding from aortotomy was identified as the reason for tamponade in the operating room. As a result of the resuscitation efforts, the subannular stent frame was deformed leading to severe AI. Initially, no AI was found after the rapid valve deployment procedure. The valve was explanted under cardiopulmonary bypass conditions, and a conventional stented pericardial valve (Trifecta; St Jude Medical Inc, St Paul, Minn) was implanted. Shortly after the reoperation, the patient died of multiorgan failure. Two patients underwent reoperation in the early postoperative period because of postoperative bleeding. One patient showed clinical signs of pericardial tamponade. No active bleeding was found intraoperatively. The remaining postoperative course was uncomplicated. The other case of postoperative bleeding leading to cardiopulmonary resuscitation has been described.

All-cause and valve-related late mortality were $5.1 \%$ (3/59) and 3.4\% (2/59), respectively (Table 3$)$. The specific causes of late deaths were urogenital infection with consecutive septicemia $(n=1)$ and heart failure $(n=2)$ (valve related). One pacemaker had to be implanted, leading to a pacemaker rate of $1.7 \%(1 / 60)$. No early and late thromboembolic events occurred. There were no cases of late valve explants. One patient had higher grade $(>+1)$ paravalvular leakage, who received a standard biological valve right in the same operation mentioned earlier. Two patients showed mild aortic regurgitation $(\mathrm{AI} \leq 1)$ caused by paravalvular leakage that was still evident after 12 months in both cases. Endocarditis, hemolysis, and structural valve deterioration were not observed. No pacemakers were implanted in the follow-up period.

\section{Echocardiographic Performance}

At discharge, the mean EAO was $1.8 \pm 0.3 \mathrm{~cm}^{2}$ and remained unchanged at 12 months. Mean transprosthetic gradient at discharge was $11.7 \pm 4.3 \mathrm{~mm} \mathrm{Hg}$ (Table 4). After 12 months, the mean gradient was $10.3 \pm$ $3.8 \mathrm{~mm} \mathrm{Hg}$ (Figure 1).

\section{DISCUSSION}

Our data show that the Edwards Intuity Valve System can be implanted with a high technical success rate of $98.1 \%$ (59/60) under minimal access conditions. Evidence of distinct advantages for minimal access AVR has been reported. $^{4-6}$ The benefits include scar reduction, shorter ventilation times, shorter intensive care unit and hospital lengths of stay, less blood loss, and faster return to routine life activities. ${ }^{4-6}$ Aris and colleagues ${ }^{17}$ did not demonstrate statistically significant benefits. Nevertheless, no worse 
TABLE 3. Early and late complications

\begin{tabular}{lcc}
\hline \multicolumn{1}{c}{ Parameter } & $\begin{array}{c}\text { Early }(<\mathbf{3 0} \mathbf{d}) \\
(\mathbf{n}=\mathbf{6 0}) \mathbf{N}(\%)\end{array}$ & $\begin{array}{c}\text { Late }(>\mathbf{3 0} \mathbf{d}) \\
(\mathbf{n}=\mathbf{5 9}) \mathbf{N}(\%)\end{array}$ \\
\hline Mortality & $1(1.7)$ & $3(5.1)$ \\
$\quad$ All-cause & $1(1.7)$ & $2(3.4)$ \\
$\quad$ Valve-related & $0(0)$ & $0(0)$ \\
Thromboembolism & $2(3.3)$ & $0(0)$ \\
Reoperation for bleeding & $1(1.7)$ & $0(0)$ \\
Paravalvular leak $(>1+)$ & $1(1.7)$ & $0(0)$ \\
Pacemaker implantation & $2(3.3)$ & $0(0)$ \\
Explant & $0(0)$ & $0(0)$ \\
Endocarditis & $0(0)$ & $0(0)$ \\
Hemolysis & $0(0)$ & $0(0)$ \\
Structural valve deterioration & &
\end{tabular}

$\mathrm{N}=$ the number of events.

outcomes for a minimally invasive approach compared with standard AVR surgery have been shown. A major point of criticism is an increase in the complexity of the operation, which might lead to increased crossclamp and bypass times. These can be identified as independent predictors of morbidity and mortality after cardiac surgery. ${ }^{18,19}$

Al-Sarraf and colleagues ${ }^{18}$ showed that crossclamp times exceeding 90 minutes are linked to an early mortality rate of approximately $5 \% .^{18}$ For every 1 -minute increase in crossclamp time, the odds of mortality increases by $2 \%$ compared with crossclamp times less than 60 minutes. ${ }^{18}$

As previously discussed, a mean crossclamp time of $26 \pm 7$ minutes with a 30 -day mortality rate of $1.7 \%$ was achieved in our series. Compared with the data of McClure and colleagues, ${ }^{20}$ with a mean crossclamp time of $75 \pm 1$ minutes and mean cardiopulmonary bypass time of $106 \pm 2$ minutes for standard AVR, this means a reduction of $63 \%$ and $46 \%$, respectively. Kocher and colleagues ${ }^{7}$ demonstrated comparable mortality rates (early mortality, $2.1 \%$; late mortality, $7.5 \%$ ) with a mean crossclamp time of $41.1 \pm 10.6$ minutes for isolated AVR using the Edwards Intuity Valve System in the Surgical Treatment of AortIc Stenosis With a Next Generation Surgical Aortic Valve (TRITON) trial. ${ }^{7}$ In the current study, minimal access AVR was performed in $48.8 \%$ of the isolated AVR cases. The operative data of our series show a further reduction of crossclamp times of $37 \%$ compared with the data from the TRITON trial. For the Enable valve system, mean crossclamp times of 55 to 58 minutes were demonstrated by Martens and colleagues. ${ }^{9,10}$ Santarpino and colleagues ${ }^{13}$ demonstrated a mean crossclamp time of $36 \pm 9$ minutes for the Perceval S valve system performing a partial sternotomy in $61 \%$ of the cases.

By taking into consideration that $100 \%(60 / 60)$ of our AVR procedures were done using the minimally invasive technique, a mean crossclamp time of $26 \pm 7$ minutes shows
TABLE 4. Echocardiographic data

\begin{tabular}{|c|c|}
\hline Parameter & Mean \pm SD \\
\hline \multicolumn{2}{|l|}{ Preoperative $(n=60)$} \\
\hline $\mathrm{P}_{\max }(\mathrm{mm} \mathrm{Hg})$ & $70.2 \pm 22.3$ \\
\hline $\mathrm{P}_{\text {mean }}(\mathrm{mm} \mathrm{Hg})$ & $46.7 \pm 17.9$ \\
\hline $\operatorname{EOA}\left(\mathrm{cm}^{2}\right)$ & $0.8 \pm 0.3$ \\
\hline \multicolumn{2}{|l|}{ Postoperative $(\mathrm{n}=59)$} \\
\hline \multicolumn{2}{|l|}{ Discharge } \\
\hline $\mathrm{P}_{\max }(\mathrm{mm} \mathrm{Hg})$ & $21.3 \pm 6.6$ \\
\hline $\mathrm{P}_{\text {mean }}(\mathrm{mm} \mathrm{Hg})$ & $11.4 \pm 4.3$ \\
\hline $\mathrm{EOA}\left(\mathrm{cm}^{2}\right)$ & $1.8 \pm 0.3$ \\
\hline \multicolumn{2}{|l|}{$19 \mathrm{~mm}(\mathrm{n}=4)$} \\
\hline $\mathrm{P}_{\max }(\mathrm{mm} \mathrm{Hg})$ & $33.5 \pm 5.0$ \\
\hline $\mathrm{P}_{\text {mean }}(\mathrm{mm} \mathrm{Hg})$ & $18.0 \pm 1.4$ \\
\hline $\operatorname{EOA}\left(\mathrm{cm}^{2}\right)$ & $1.3 \pm 0.4$ \\
\hline \multicolumn{2}{|l|}{$21 \mathrm{~mm}(\mathrm{n}=17)$} \\
\hline $\mathrm{P}_{\max }(\mathrm{mm} \mathrm{Hg})$ & $21.4 \pm 6.4$ \\
\hline $\mathrm{P}_{\text {mean }}(\mathrm{mm} \mathrm{Hg})$ & $12.2 \pm 3.8$ \\
\hline $\operatorname{EOA}\left(\mathrm{cm}^{2}\right)$ & $1.5 \pm 0.2$ \\
\hline \multicolumn{2}{|l|}{$23 \mathrm{~mm}(\mathrm{n}=17)$} \\
\hline $\mathrm{P}_{\max }(\mathrm{mm} \mathrm{Hg})$ & $20.9 \pm 5.9$ \\
\hline $\mathrm{P}_{\text {mean }}(\mathrm{mm} \mathrm{Hg})$ & $11.8 \pm 3.1$ \\
\hline $\mathrm{EOA}\left(\mathrm{cm}^{2}\right)$ & $1.7 \pm 0.4$ \\
\hline \multicolumn{2}{|l|}{$25 \mathrm{~mm}(\mathrm{n}=16)$} \\
\hline $\mathrm{P}_{\max }(\mathrm{mm} \mathrm{Hg})$ & $20.8 \pm 5.0$ \\
\hline $\mathrm{P}_{\text {mean }}(\mathrm{mm} \mathrm{Hg})$ & $10.5 \pm 3.0$ \\
\hline EOA $\left(\mathrm{cm}^{2}\right)$ & $2.1 \pm 0.3$ \\
\hline \multicolumn{2}{|l|}{$27 \mathrm{~mm}(\mathrm{n}=6)$} \\
\hline $\mathrm{P}_{\max }(\mathrm{mm} \mathrm{Hg})$ & $15.0 \pm 4.2$ \\
\hline $\mathrm{P}_{\text {mean }}(\mathrm{mm} \mathrm{Hg})$ & $8.5 \pm 3.5$ \\
\hline $\mathrm{EOA}\left(\mathrm{cm}^{2}\right)$ & $2.4 \pm 0.5$ \\
\hline \multicolumn{2}{|c|}{ 12-mo follow-up $(\mathrm{n}=56)$} \\
\hline $\mathrm{P}_{\max }(\mathrm{mm} \mathrm{Hg})$ & $20.6 \pm 4.1$ \\
\hline $\mathrm{P}_{\text {mean }}(\mathrm{mm} \mathrm{Hg})$ & $10.3 \pm 3.8$ \\
\hline $\operatorname{EOA}\left(\mathrm{cm}^{2}\right)$ & $1.8 \pm 0.3$ \\
\hline \multicolumn{2}{|l|}{$19 \mathrm{~mm}(\mathrm{n}=4)$} \\
\hline $\mathrm{P}_{\max }(\mathrm{mm} \mathrm{Hg})$ & $30.5 \pm 4.7$ \\
\hline $\mathrm{P}_{\text {mean }}(\mathrm{mm} \mathrm{Hg})$ & $17.2 \pm 1.5$ \\
\hline EOA $\left(\mathrm{cm}^{2}\right)$ & $1.2 \pm 0.3$ \\
\hline \multicolumn{2}{|l|}{$21 \mathrm{~mm}(\mathrm{n}=17)$} \\
\hline $\mathrm{P}_{\max }(\mathrm{mm} \mathrm{Hg})$ & $19.7 \pm 5.4$ \\
\hline $\mathrm{P}_{\text {mean }}(\mathrm{mm} \mathrm{Hg})$ & $10.2 \pm 3.1$ \\
\hline $\mathrm{EOA}\left(\mathrm{cm}^{2}\right)$ & $1.5 \pm 0.3$ \\
\hline \multicolumn{2}{|l|}{$23 \mathrm{~mm}(\mathrm{n}=15)$} \\
\hline $\mathrm{P}_{\max }(\mathrm{mm} \mathrm{Hg})$ & $19.4 \pm 4.4$ \\
\hline $\mathrm{P}_{\text {mean }}(\mathrm{mm} \mathrm{Hg})$ & $10.1 \pm 3.3$ \\
\hline EOA $\left(\mathrm{cm}^{2}\right)$ & $1.8 \pm 0.4$ \\
\hline \multicolumn{2}{|l|}{$25 \mathrm{~mm}(\mathrm{n}=14)$} \\
\hline $\mathrm{P}_{\max }(\mathrm{mm} \mathrm{Hg})$ & $19.3 \pm 4.5$ \\
\hline $\mathrm{P}_{\text {mean }}(\mathrm{mm} \mathrm{Hg})$ & $10.9 \pm 3.5$ \\
\hline $\mathrm{EOA}\left(\mathrm{cm}^{2}\right)$ & $2.1 \pm 0.3$ \\
\hline \multicolumn{2}{|l|}{$27 \mathrm{~mm}(\mathrm{n}=6)$} \\
\hline $\mathrm{P}_{\max }(\mathrm{mm} \mathrm{Hg})$ & $14.7 \pm 4.4$ \\
\hline $\mathrm{P}_{\text {mean }}(\mathrm{mm} \mathrm{Hg})$ & $6.8 \pm 3.8$ \\
\hline $\operatorname{EOA}\left(\mathrm{cm}^{2}\right)$ & $2.4 \pm 0.4$ \\
\hline
\end{tabular}

$E A O$, Effective orifice area; $S D$, standard deviation. 


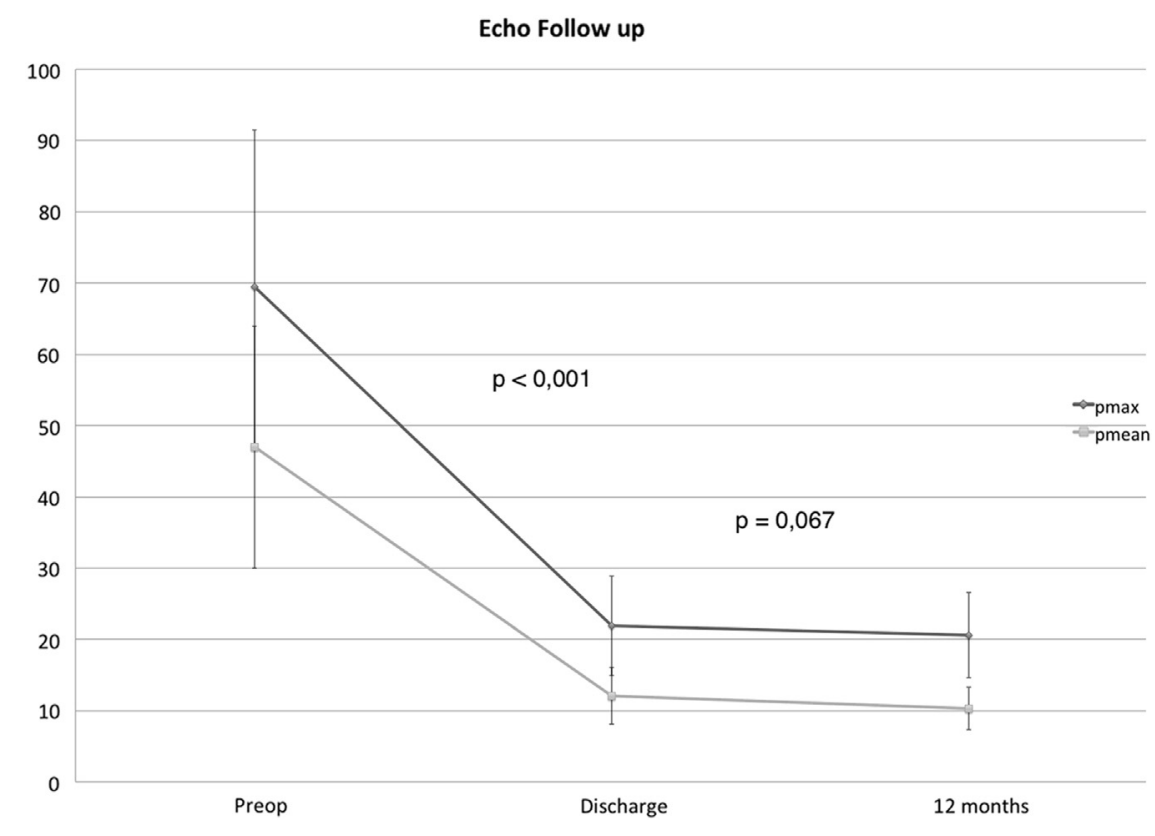

FIGURE 1. Echocardiographic performance at discharge and after 12 months.

the clear potential of the Intuity valve system to simplify and therefore accelerate the entire AVR procedure, especially in minimally invasive surgery. A further decrease in crossclamp times may be expected with increasing experience. The data suggest that we did not encounter much of a learning curve, which underlines the ease of implantation and the simplicity of teaching the procedure. A mean crossclamp time of $26 \pm 7$ minutes is the shortest crossclamp time for standard AVR reported in the literature. To date, the current series represents one of the largest experiences with the Intuity rapid deployment valve system in a minimally invasive setting.

A further step toward less invasiveness is the right anterior thoracotomy approach. Miceli and colleagues ${ }^{21}$ showed excellent results with an early mortality rate of $0.7 \%$ in a high-risk patient collective using this technique in combination with the Perceval S valve. Furthermore, distinct advantages concerning postoperative atrial fibrillation, ventilation times, and hospital length of stay compared with partial sternotomy were shown by the same group. ${ }^{22}$ Laufer and colleagues $^{23}$ were the first to use the Intuity valve system in a right anterior thoracotomy setting and showed the suitability for this access.

A noticeable difference between mean cardiopulmonary bypass ( $56 \pm 12$ minutes) and crossclamp ( $26 \pm 7$ minutes) times was observed. Factors that contribute to this difference are difficulties with the vent insertion in a minimally invasive setting within an obese patient collective, our extensive reperfusion and de-airing strategy, minor bleeding problems at the vent cannulation site, and bleeding from aortotomy. We perform de-airing with a needle vent under suction in the ascending aorta with the heart ejecting. Weaning from bypass is started only if air artifacts are absolutely minimized in transesophageal echocardiography. A further reduction of this gap between ultra-fast crossclamp times and the described bypass times by optimizing those factors is certainly needed. The reperfusion and de-airing strategy especially could be reconsidered in terms of reducing cardiopulmonary bypass time in this older patient collective.

A remarkable finding of this series is the low incidence of pacemaker implantation in the early $(1.7 \%)(1 / 60)$ and late $(0 \%)(0 / 59)$ postoperative periods; rates of $5 \%(7 / 141)$ and $0.8 \%(1 / 128)$, respectively, were reported in the TRITON study.

Paravalvular leakage has a major impact on patient outcome. One thing we learned from the Placement of Aortic Transcatheter Valves (PARTNER) trial and several publications is the association of paravalvular leakage with an increased rate of late mortality. ${ }^{2}$ The effect of aortic regurgitation on mortality was proportional to the severity of regurgitation. Even mild aortic regurgitation causes an increase in late deaths. ${ }^{2,3}$ An aortic regurgitation rate $(>1)$ of $1.7 \%$ for the early period and $0.0 \%$ for the late period can be found in this series. The high-grade aortic regurgitation, which was seen intraoperatively in 1 patient, was mainly related to incorrect sizing.

Two patients, aged 79 and 76 years at the time of operation, died of heart failure during the 12-month follow-up period. Both received a 23-mm valve that showed normal valve function with no paravalvular leakage at 
discharge. The mean transprosthetic gradients at discharge were 10 and $12 \mathrm{~mm} \mathrm{Hg}$, respectively. Both patients were in New York Heart Association class IV before the operation. A massive ventricular hypertrophy was seen on echocardiography, with normal systolic ventricular function but severe diastolic dysfunction. Although no autopsy was performed in these patients, it seems unlikely that the valve was the reason for heart failure. Nevertheless, this has to be considered the reason for sudden unexplained death and was therefore counted as valve-related mortality according to the guidelines for reporting mortality and morbidity after cardiac valve interventions. ${ }^{24}$

In contrast to the Enable and Perceval S system, the Intuity rapid deployment valve system is not collapsed, which might affect the long-term outcome. The valve design is based on the Edwards Perimount platform enhanced by a balloon-expandable stent frame anchoring the valve system in the subannular region. To date, the Perimount valve has been implanted in more than 500,000 patients. ${ }^{20,25-30}$ Therefore, there is extensive experience concerning the hemodynamic performance and long-term efficacy. ${ }^{25-30}$

The Perimount valve is characterized by a low-profile, supra-annular design, and unique anticalcification technology. The hemodynamic performance of the Intuity rapid deployment valve system in this study is comparable to the hemodynamic performance reported in the literature for the Perimount valve. Dellgren and colleagues ${ }^{30}$ report transvalvular peak and mean pressure differences measured with Doppler echocardiography of $23.2 \pm 9.6 \mathrm{~mm} \mathrm{Hg}$ and $12.3 \pm 4.8 \mathrm{~mm} \mathrm{Hg}$, respectively. The mean effective orifice area (EOA) was $1.3 \pm 0.3 \mathrm{~cm}^{2}$ after a mean follow-up period of $60 \pm 31$ months. $^{30}$ Dalmau and colleagues ${ }^{29}$ found a mean EOA of $1.9 \pm 0.4 \mathrm{~cm}^{2}$ and a mean pressure gradient of $10.3 \pm 3.4 \mathrm{~mm} \mathrm{Hg}$ at 1 year. Cohen and colleagues ${ }^{28}$ reported a mean EOA of $1.9 \pm 0.6 \mathrm{~cm}^{2}$ and a mean pressure gradient of $7.1 \pm 3.7 \mathrm{~mm} \mathrm{Hg}$ at 1 year. In addition, favorable long-term hemodynamic performance of the Carpentier-Edwards Perimount valve at 9 years, with a mean EOA of $1.5 \pm 0.6 \mathrm{~cm}^{2}$ and a mean pressure gradient of $10.9 \pm 3.7 \mathrm{~mm} \mathrm{Hg}$, is being reported. ${ }^{28}$ Borger and colleagues ${ }^{27}$ reported a mean EOA of $1.40 \pm 0.24 \mathrm{~cm}^{2}$ and a mean pressure gradient of $10.4 \pm 4.0 \mathrm{~mm} \mathrm{Hg}$ for the Perimount Magna valve. A mean EOA of $1.8 \pm 0.3 \mathrm{~cm}^{2}$ and a mean pressure gradient of $11.4 \pm 4.3 \mathrm{~mm} \mathrm{Hg}$ were found in our series. The specific EOAs of the separate valve sizes are comparable to those found for the Perimount Magna valve. ${ }^{27}$

The history of coronary interventions versus bypass surgery shows remarkable parallels to contemporary developments in transcatheter valve therapy. A central issue is a clear tendency toward less-invasive procedures at the cost of long-term efficacy. A way to encounter this challenge is to offer less-invasive surgery with no compromises concerning long-term outcomes. Thus, rapid deployment or sutureless valves represent a specific and useful enhancement of the armamentarium in the treatment of aortic valve disease, and is one step further in the promotion of minimal access approaches.

\section{Study Limitations}

This was a nonrandomized, single-center observational study without a concurrent control group. Possible selection and performance biases due to a nonblinded study design, as well as attrition biases resulting from missing data points, may represent other important study limitations. In addition, the reported data extend up to only 12 months, and long-term performance and complications may differ over an extended period of time.

\section{CONCLUSIONS}

Minimal access rapid deployment AVR using the Edwards Intuity valve system can be performed safely and efficaciously. By facilitating minimally invasive surgery, reproducible short myocardial ischemic and bypass times can be achieved. Good hemodynamics comparable to other sutureless or rapid deployment valves and low complication rates are demonstrated. The low rates of paravalvular leakage are especially remarkable. On the basis of the Perimount family of valves, long-term durability and hemodynamic performance should be comparable to this type of valve. Furthermore, no collapsing of the valve is necessary before valve deployment, which may yield potential benefits. Nevertheless, future follow-up investigation has to be awaited to gain more data concerning durability and safety issues. The new occurrence of paravalvular leaks has to be closely tracked. Further prospective, randomized, controlled studies are needed to evaluate the beneficial effects of rapid deployment or sutureless AVR, especially in a minimally invasive setting, compared with standard AVR.

\section{References}

1. Beckmann A, Hamm C, Figulla HR, Cremer J, Kuck KH, Lange R, et al. The German Aortic Valve Registry (GARY): a nationwide registry for patients undergoing invasive therapy for severe aortic valve stenosis. J Thorac Cardiovasc Surg. 2012;60:319-25.

2. Smith CR, Leon MB, Mack MJ, Miller DC, Moses JW, Svensson LG, et al; PARTNER Trial Investigators. Transcatheter versus surgical aortic-valve replacement in high-risk patients. N Engl J Med. 2011;364:2187-98.

3. Kodali SK, Williams MR, Smith CR, Svensson LG, Webb JG, Makkar RR, et al; PARTNER Trial Investigators. Two-year outcomes after transcatheter or surgical aortic-valve replacement. $N$ Engl J Med. 2012;366:1686-95.

4. Doll N, Borger MA, Hain J, Bucerius J, Walther T, Gummert JF, et al. Minimal access aortic valve replacement: effects on morbidity and resource utilization. Ann Thorac Surg. 2002;74:S1318-22.

5. Tabata M, Umakanthan R, Cohn LH, Bolman RM 3rd, Shekar PS, Chen FY, et al Early and late outcomes of 1000 minimally invasive aortic valve operations. Eur J Cardiothorac Surg. 2008;33:537-41.

6. Dogan S, Dzemali O, Wimmer-Greinecker G, Derra P, Doss M, Khan MF, et al. Minimally invasive versus conventional aortic valve replacement. J Heart Valve Dis. 2003;12:76-80.

7. Kocher AA, Laufer G, Haverich A, Shrestha M, Walther T, Misfeld M, et al. One-year outcomes of the TRITON trial: a prospective multicenter study of rapid 
deployment aortic valve replacement with the EDWARDS INTUITY valve system. J Thorac Cardiovasc Surg. 2013;145:110-5.

8. Flameng W, Herregods MC, Hermans H, Van der Mieren G, Vercalsteren M, Poortmans G, et al. Effect of sutureless implantation of the Perceval S aortic valve bioprosthesis on intraoperative and early postoperative outcomes. J Thorac Cardiovasc Surg. 2011;142:1453-7.

9. Martens S, Ploss A, Sirat S, Miskovic A, Moritz A, Doss M. Sutureless aortic valve replacement with the 3 f Enable aortic bioprosthesis. Ann Thorac Surg. 2009;87:1914-7.

10. Martens S, Sadowski J, Eckstein FS, Bartus K, Kapelak B, Sievers HH, et al. Clinical experience with the ATS $3 f$ Enable(R) sutureless bioprosthesis. Eur J Cardiothorac Surg. 2011;40:749-55.

11. Cerillo AG, Bevilacqua S, Farneti PA, Concistrè G, Glauber M. Sutureless aortic valve replacement through a right minithoracotomy. J Heart Valve Dis. 2012;21: 168-71.

12. Folliguet TA, Laborde F, Zannis K, Ghorayeb G, Haverich A, Shrestha M. Sutureless Perceval aortic valve replacement: results of two European centers. Ann Thorac Surg. 2012;93:1483-8.

13. Santarpino G, Pfeiffer S, Schmidt J, Concistre G, Fischlein T. Sutureless aortic valve replacement: first-year single-center experience. Ann Thorac Surg. 2012; 94:504-9.

14. Butchart EG, Gohlke-Bärwolf C, Antunes MJ, Tornos P, De Caterina R, Cormier B, et al. Recommendations for the management of patients after heart valve surgery. Eur Heart J. 2005;26:2463-71.

15. Zoghbi WA, Chambers JB, Dumesnil JG, Foster E, Gottdiener JS, Grayburn PA, et al. Recommendations for evaluation of prosthetic valves with echocardiography and Doppler ultrasound: a report from the American Society of Echocardiography's Guidelines and Standards Committee and the Task Force on Prosthetic Valves, developed in conjunction with the American College of Cardiology Cardiovascular Imaging Committee, Cardiac Imaging Committee of the American Heart Association, the European Association of Echocardiography, a registered branch of the European Society of Cardiology, the Japanese Society of Echocardiography and the Canadian Society of Echocardiography, endorsed by the American College of Cardiology Foundation, American Heart Association, European Association of Echocardiography, a registered branch of the European Society of Cardiology, the Japanese Society of Echocardiography, and Canadian Society of Echocardiography. J Am Soc Echocardiogr. 2009;22:975-1014.

16. Leon MB, Piazza N, Nikolsky E, Blackstone EH, Cutlip DE, Kappetein AP, et al. Standardized endpoint definitions for transcatheter aortic valve implantation clinical trials. J Am Coll Cardiol. 2011;57:253-69.

17. Aris A, Camara ML, Montiel J, Delgado LJ, Galan J, Litvan H. Ministernotomy versus median sternotomy for aortic valve replacement: a prospective, randomized study. Ann Thorac Surg. 1999;67:1583-8.
18. Al-Sarraf N, Thalib L, Hughes A, Houlihan M, Tolan M, Young V, et al. Cross-clamp time is an independent predictor of mortality and morbidity in low- and high-risk cardiac patients. Int J Surg. 2011;9:104-9.

19. Salis S, Mazzanti VV, Merli G, Salvi L, Tedesco CC, Veglia F, et al. Cardiopulmonary bypass duration is an independent predictor of morbidity and mortality after cardiac surgery. J Cardiothorac Vasc Anesth. 2008;22:814-22.

20. McClure RS, Narayanasamy N, Wiegerinck E, Lipsitz S, Maloney A, Byrne JG, et al. Late outcomes for aortic valve replacement with the Carpentier-Edwards pericardial bioprosthesis: up to 17-year follow-up in 1,000 patients. Ann Thorac Surg. 2010;89:1410-6.

21. Miceli A, Santarpino G, Pfeiffer S, Murzi M, Gilmanov D, Concistré G, et al. Minimally invasive aortic valve replacement with Perceval S sutureless valve: early outcomes and one-year survival from two European centers. J Thorac Cardiovasc Surg. March 4, 2014 [Epub ahead of print].

22. Miceli A, Murzi M, Gilmanov D, Fugà R, Ferrarini M, Solinas M, et al. Minimally invasive aortic valve replacement using right minithoracotomy is associated with better outcomes than ministernotomy. J Thorac Cardiovasc Surg. 2014;148:133-7.

23. Laufer G, Wiedemann D, Vadehra A, Rosenhek R, Binder T, Kocher A. CMP27 mini-thoracotomy for sutureless-rapid-deployment aortic valve replacement: initial single-center experience. Innovations (Phila). 2013;8:86-109.

24. Akins CW, Miller DC, Turina MI, Kouchoukos NT, Blackstone EH, Grunkemeier GL, et al. Guidelines for reporting mortality and morbidity after cardiac valve interventions. J Thorac Cardiovasc Surg. 2008;135:732-8.

25. Frater RW, Salomon NW, Rainer WG, Cosgrove DM III, Wickham E. The Carpentier-Edwards pericardial aortic valve: intermediate results. Ann Thorac Surg. 1992;53:764-71.

26. Le Tourneau T, Vincentelli A, Fayad G, Savoye C, Fabre OH, Prat A, et al. Tenyear echocardiographic and clinical follow-up of aortic Carpentier-Edwards pericardial and supraannular prosthesis. Ann Thorac Surg. 2002;74:2010-5.

27. Borger MA, Nette AF, Maganti M, Feindel CM. Carpentier-Edwards Perimount Magna valve versus Medtronic Hancock II. Ann Thorac Surg. 2007; 83:2054-9.

28. Cohen G, Zagorski B, Christakis GT, Joyner CD, Vincent J, Sever J, et al. Are stentless valves hemodynamically superior to stented valves? Long-term follow-up of a randomized trial comparing Carpentier-Edwards pericardial valve with the Toronto Stentless Porcine Valve. J Thorac Cardiovasc Surg. 2010;139: 848-59.

29. Dalmau MJ, Gonzalez-Santos JM, Blazquez JA, Sastre JA, López-Rodríguez J, Bueno M, et al. Hemodynamic performance of the Medtronic Mosaic and Perimount Magna aortic bioprostheses. Eur J Cardiothorac Surg. 2011;39:844-52.

30. Dellgren G, David TE, Raanani E, Armstrong S, Ivanov J, Rakowski H. Late hemodynamic and clinical outcomes of aortic valve replacement with the Carpentier-Edwards Perimount pericardial bioprosthesis. J Thorac Cardiovasc Surg. 2002;124:146-54. 